Check for updates

Cite this: RSC Adv., 2019, 9, 8608

Received 3rd January 2019 Accepted 5th March 2019

DOI: $10.1039 / \mathrm{c} 9 \mathrm{ra} 00038 \mathrm{k}$ rsc.li/rsc-advances

\title{
Effect of molecular flexibility on the rheological and filtration properties of synthetic polymers used as fluid loss additives in water-based drilling fluid
}

\author{
Qi Chu ${ }^{\text {ab }}$ and Ling Lin (iD)*cd
}

The effect of molecular flexibility on the rheological and filtration properties of synthetic polymers used as fluid loss additives in water-based drilling fluid was investigated. A new synthetic polymer (PAANS) comprising acrylamide (AM), 2-acrylamido-2-methyl-1-propane sulfonic acid (AMPS), N-vinyl-2pyrrolidone (NVP) and potassium 2,5-dihydroxybenzenesulfonate (DHBS) was synthesized, in which phenyl groups were introduced in the backbone. Two other comparative polymers, PAAN and PAANS, were also prepared following the same synthesis procedure. PAAN comprises AM, AMPS and NVP, while PAANS consists of AM, AMPS, NVP and sodium 4-styrenesulfonate (SSS). PAAN, PAAND and PAANS were characterized by ${ }^{1} \mathrm{H}$ NMR and elemental analysis, and the molecular weight was determined by static light scattering (SLS). The rheological properties, filtration properties and performance sustainability were investigated. Using a rheological properties measurement test, the apparent viscosity (AV), plastic viscosity (PV) and yield point (YP) of the Na-MMT/PAAND system at a concentration of $2.0 \%$ were 18.0 $\mathrm{mP} \mathrm{s}, 12.0 \mathrm{mP}$ s and $6.0 \mathrm{~Pa}$, respectively, after a thermal aging test at $240{ }^{\circ} \mathrm{C}$ for $16 \mathrm{~h}$. These values are much higher than those of the corresponding Na-MMT/PAAN and Na-MMT/PAANS systems. The API filtration loss volume $\left(\mathrm{FL}_{\mathrm{API}}\right)$ and high-temperature/high-pressure filtrate volume ( $\mathrm{FL}$ HTHP) of the $\mathrm{Na}$ MMT/PAAND system at a concentration of $2.0 \%$ were $12.0 \mathrm{~mL}$ and $30.0 \mathrm{~mL}$, respectively, after a thermal aging test at $240{ }^{\circ} \mathrm{C}$ for $16 \mathrm{~h}$. These values are much lower than those of the Na-MMT/PAAN and NaMMT/PAANS systems. Compared with PAAN and PAANS, PAAND presents the best performance sustainability after multiple shearing and thermal aging tests. At the same temperature, the order of maintaining rheological performance and controlling the $\mathrm{FL}_{\mathrm{API}}$ and $\mathrm{FL}_{\mathrm{HTHP}}$ was PAAND > PAANS > PAAN in Na-MMT/PAANS-based drilling fluid at high temperature. Increasing the percentage of rigid monomers in the backbone was found to be conducive to maintaining the rheological stability and improving the filtration properties at high temperature. The control mechanism of fluid loss was investigated through adsorption tests using the method of thermal filtration, assessing particle size distribution on a laser diffraction particle size analyzer (LPSA) and examining filter cake morphologies using an environmental scanning electron microscope (ESEM). The results reveal that the introduction of rigid monomers into the synthetic polymer backbone can effectively improve the adsorption capacity of the polymer on the clay surface, obstruct the aggregation of clay particles, and improve the quality of filter cakes at high temperatures.

\section{Introduction}

Drilling fluids, also referred to as "drilling muds", play an important role in drilling operations. They perform essential tasks including lubricating the drilling tool and drill pipe that

\footnotetext{
${ }^{a}$ State Key Laboratory of Shale Oil and Gas Enrichment Mechanisms and Effective Development, Beijing 100101, China. E-mail: 190261829@qq.com

${ }^{b}$ Sinopec Research Institute of Petroleum Engineering, Sinopec, Beijing 100101, China 'School of Chemistry and Chemical Engineering, Southwest Petroleum University, Chengdu 610500, China

${ }^{\text {a}}$ Oil \& Gas Field Applied Chemistry Key Laboratory of Sichuan Province, Southwest Petroleum University, Chengdu 610500, China
}

carries the tool, suspending and transporting formation cuttings to the surface for screening and disposal, holding the cuttings in suspension in the event of a shutdown in the drilling and pumping of the drilling fluid, and counterbalancing formation pressures to prevent the inflow of gas, oil or water from permeable rocks, which may be encountered at various levels in the drilling process. ${ }^{1-4}$ One of the most important functions of drilling fluid, the filtration performance, is to form an impervious filter cake on the wall of the wellbore, prevent water leakage, block pressure transport from the wellbore to the formation, and maintain the stability of the well wall. Adding a fluid loss additive is the best way to improve the filtration performance of drilling fluid. ${ }^{5-7}$ Currently, there are two kinds 
of fluid loss additives: natural polymer compounds (e.g., starch, xanthan gum, carboxymethyl cellulose and polyanionic cellulose lignite) and synthetic polymers. ${ }^{8-13}$ However, as oil and gas exploration is increasingly focused on deep formations, synthetic polymers, such as 2-acrylamido-2-methylpropane sulfonic acid (AMPS) multi-copolymers, are most widely used as fluid loss additives in drilling fluid because of their high temperature resistance. At present, many modifications of high temperature fluid loss additives are based on AMPS multicopolymers. ${ }^{14-16}$

In recent decades, research has considerably enriched our knowledge about the mechanisms behind how these synthetic polymers prevent fluid loss. It has shown that synthetic polymers as fluid loss additives contain at least two groups: an adsorption group and a hydration group. Adsorption groups, such as $-\mathrm{OH},-\mathrm{SiOH},-\mathrm{CONH}_{2}$ and cationic groups, are used to enhance the interaction between the polymer and bentonite. The polymeric fluid loss additive can therefore better adsorb on the bentonite surface via hydrogen bonding, coordination bonding or ionic bonding to raise the $\zeta$ potential and hydrated shell thickness of the bentonite particles. Hydration groups, such as $-\mathrm{COO}^{-}$and $-\mathrm{SO}_{3}{ }^{-}$, are used to improve the dispersion properties of bentonite. They reduce the attractions between bentonite particles by electrostatic stabilization, strengthen the bentonite structure, and help to plug the filter cake holes. ${ }^{17,18}$ Therefore, recent efforts to modify polymeric fluid loss additives have mainly been focused on adsorption and hydration groups. However, it is worth noting that the temperature resistance of a polymeric fluid loss additive obtained by changing the types and proportions of adsorbed and hydrated groups in the molecule rarely exceeds $230{ }^{\circ} \mathrm{C}$. In order to further improve the temperature resistance of polymeric fluid loss additives, other molecular modification methods must be considered.

In other polymer fields, since Hill and Walker first pointed out that the incorporation of aromatic segments into a polymer generally results in a noticeable increase in its thermal stability, considerable research has been conducted to improve the rigidity of molecules by incorporating or grafting aromatic units. ${ }^{19-21}$ Many of these aromatic polymers have been commercialized, such as aromatic polyamides, polyimides, polyesters, polysulfones, and heterocyclic polymers. ${ }^{22-27}$ This method can also be applied to the modification of polymeric fluid loss additives. Polymeric fluid loss additives with high temperature resistance usually tend to contain more aromatic units in their structure. Wan et al. used the inverse microemulsion polymerization method to synthesize copolymers of different hydrophilic monomers, such as acrylamide (AM), acrylic acid (AA) and sodium 4-styrenesulfonate (SSS). The maximum thermal stability of the AM/AA/SSS copolymer was found to be higher than $230{ }^{\circ} \mathrm{C}^{28} \mathrm{Ma}$ et al. used the free radical polymerization method to synthesize copolymers of different hydrophilic monomers, such as AM, AMPS, diallyl dimethyl ammonium chloride (DMDAAC) and vinylphenyl sulfonate (VPS). In their study, the API filtration loss volume ( $\left.\mathrm{FL}_{\mathrm{API}}\right)$ of freshwater drilling fluid containing $1.25 \%$ polymeric fluid loss additive was only $4.8 \mathrm{~mL}$, and it was $19.2 \mathrm{~mL}$ after aging at $200{ }^{\circ} \mathrm{C}$ for $16 \mathrm{~h}^{29}$
This paper concerns the investigation of the relationship between the flexibility and thermal stability of polymeric fluid loss additives, in order to enhance the temperature resistance of polymeric fluid loss additives by introducing rigid monomers into their molecular structures. In this study, SSS and potassium 2,5-dihydroxybenzenesulfonate (DHBS) were chosen as the rigid monomers, which were introduced into an AM/AMPS/ NVP copolymer. SSS was used as a rigid monomer for the construction of part of the side chain of AM/AMPS/NVP/SSS. DHBS was used as a rigid monomer for the construction of part of the main chain of AM/AMPS/NVP/DHBS. Three different kinds of copolymers were synthesized to compare the effect of the structure on the thermal stability of rheological and filtration properties.

\section{Experimental}

\section{Materials}

Pristine sodium montmorillonite (Na-MMT) was obtained as a commercial product from Xinjiang Xiazijie bentonite Co., Ltd., and it had a cation exchange capacity (CEC) of 118.4 mequiv./100 g.

Acrylamide (AM), 2-acrylamido-2-methyl-1-propane sulfonic acid (AMPS), $N$-vinyl-2-pyrrolidone (NVP), sodium 4-styrenesulfonate (SSS), and potassium 2,5-dihydroxybenzenesulfonate (DHBS) were purchased from Shanghai Aladdin Bio-chem Technology Co., Ltd., and were used without further purification. The initiator was horseradish peroxidase (HRP, enzyme activity $\geq 200$ units per $\mathrm{mg}$ solid), which was purchased from Shanghai Aladdin Reagent Co. Hydrogen peroxide $\left(\mathrm{H}_{2} \mathrm{O}_{2}\right.$, $10.0 \%$, w/v) from Chengdu Huabo Chemical Reagent Co. and acetylacetone (ACAC), dipotassium hydrogen phosphate, sodium hydroxide, 1,4-dioxane, acetone and ethanol from Chengdu Kelong Chemical Reagent Co. of analytical grade were used as catalyzer, neutralizer and solvent respectively.

\section{Synthesis}

The polymerization was carried out in a four-necked round bottom flask equipped with a stirrer, thermometer, nitrogen gas inlet and condenser. Firstly, a buffer solution of $\mathrm{pH}=6.5$ was obtained by diluting $1.36 \mathrm{~g}$ dipotassium hydrogen phosphate with $0.1 \mathrm{~mol} \mathrm{~L}^{-1}$ sodium hydroxide solution of $30.4 \mathrm{~mL}$ with water to $200 \mathrm{~mL}$. Then, $100 \mathrm{mg}$ HRP was dissolved in $50 \mathrm{~mL}$ water and stored at $4{ }^{\circ} \mathrm{C}$. Secondly, AM, AMPS, NVP and DHBS were added to 1,4-dioxane, and the mixture was then transferred into the above flask. Thirdly, $200 \mathrm{~mL}$ buffer solution was added to the reaction flask after $30 \mathrm{~min}$ of deoxygenation with $\mathrm{N}_{2}$. After mixing, the HRP solution and ACAC were added and then the mixture was heated to $50{ }^{\circ} \mathrm{C}$. The reaction was stopped after $12 \mathrm{~h}$. During the whole polymerization process, $\mathrm{H}_{2} \mathrm{O}_{2}$ solution was injected gradually into the flask through a plastic septum by using a syringe. Finally, the product was cut into small pieces by hand and vacuum-dried at $75{ }^{\circ} \mathrm{C}$ for $24 \mathrm{~h}$ and stored in desiccators.

The molar ratio of AM, AMPS, NVP and DHBS was $60: 20: 12: 8$. The total weight percent of the four monomers 
in 1,4-dioxane was $10.0 \%$. The weight of the HRP solution compared with the monomers was $0.02 \%$. The weight of ACAC and $\mathrm{H}_{2} \mathrm{O}_{2}$ solution compared with the monomers was $0.05 \%$ and $0.08 \%$, respectively. Poly(AM/AMPS/NVP/DHBS) was named PAAND. Poly(AM/AMPS/NVP) and poly(AM/AMPS/NVP/SSS) were named PAAN and PAANS, respectively, which were synthesized and dried under the same polymerization conditions, but the DHBS monomer was not added in PAAN and the DHBS monomer was replaced with SSS in PAANS. The catalytic mechanism of HRP and copolymerization schematic diagram of PAAND are shown in Fig. 1 and 2.

\section{Characterization}

PAAN, PAAND and PAANS were precipitated with ethanol for $12 \mathrm{~h}$ and washed three times with acetone, thus removing the unreacted monomer. The products were dried at $40{ }^{\circ} \mathrm{C}$. Then, PAAN, PAAND and PAANS were removed from the precipitated sample by Soxhlet extraction with a $60: 40(\mathrm{v} / \mathrm{v})$ mixture of ethylene glycol and acetic acid. Finally, PAAN, PAAND and PAANS were washed with ethanol, and were dried in a vacuum oven at $40{ }^{\circ} \mathrm{C}$ until the samples reached a constant weight.

${ }^{1} \mathrm{H}$ nuclear magnetic resonance $\left({ }^{1} \mathrm{H} \mathrm{NMR}\right)$ analysis was used to determine the molecular structures and functional groups. ${ }^{1} \mathrm{H}$ NMR analysis was conducted on an Avance II $400 \mathrm{MHz}$ NMR

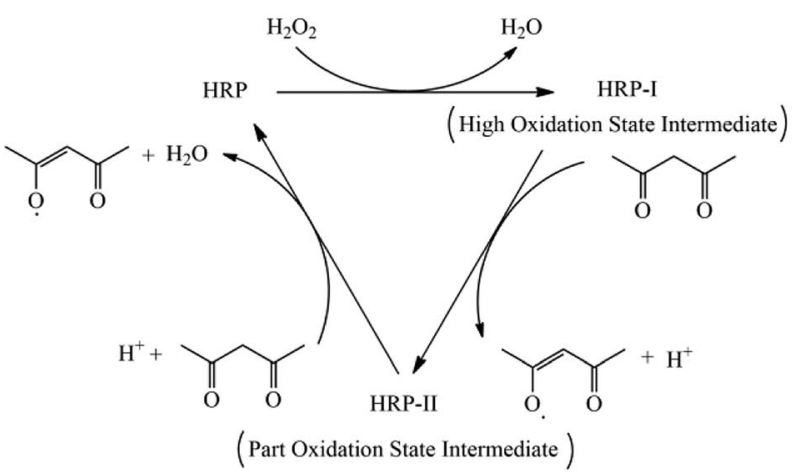

Fig. 1 The catalytic mechanism of HRP.

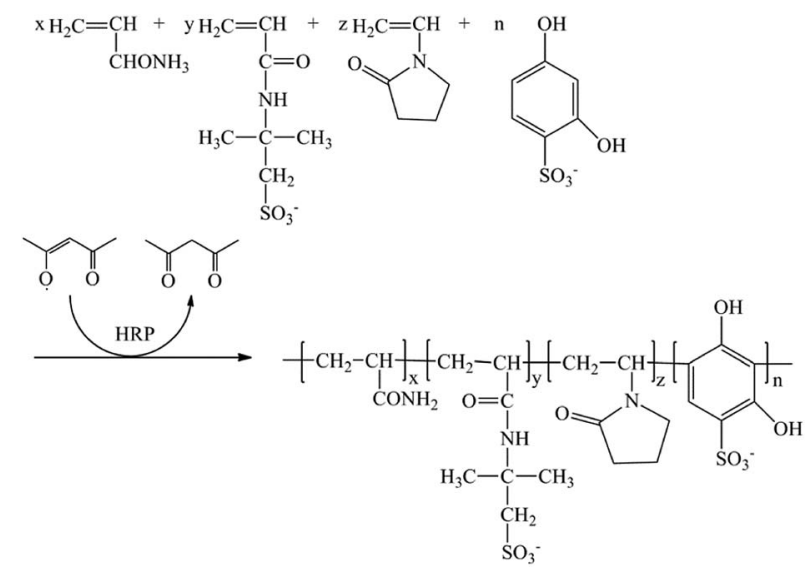

Fig. 2 The copolymerization schematic diagram of PAAND. spectrometer (Bruker Instrument Co. Ltd., Switzerland) to obtain proton nuclear magnetic resonance spectra. $\mathrm{D}_{2} \mathrm{O}$ was used for the field-frequency lock, and the observed ${ }^{1} \mathrm{H}$ chemicalshifts were reported in parts per million (ppm). The elemental analysis of PAAN, PAAND and PAANS was conducted on an EA 2400II elemental analyzer (PerkinElmer Instrument Co. Ltd., USA) to determine the carbon, nitrogen, oxygen and sulfur content. Determination of the molecular weight distributions of PAAN, PAAND and PAANS was conducted through static light scattering (SLS) measurements (Wyatt Technology Inc., Canada) using a Gs-As laser (658 $\mathrm{nm}$ and $40 \mathrm{~mW}$ ).

\section{Performance evaluation}

Drilling fluid was prepared according to American Petroleum Institute (API) specifications. The water-based drilling fluid (4.0\% prehydrated Na-MMT) was made up by maintaining the Na-MMT to $\mathrm{H}_{2} \mathrm{O}$ weight ratio at $4: 100$. Prior to use, the waterbased drilling fluids were aged for $24 \mathrm{~h}$ at room temperature to hydrate.

A certain amount $(\mathrm{w} / \mathrm{v})$ of PAAN, PAAND and PAANS was dissolved in the water-based drilling fluid with stirring at $10000 \mathrm{rpm}$ for $20 \mathrm{~min}$. Thermal aging tests of Na-MMT/PAAN, Na-MMT/PAAND and Na-MMT/PAANS were carried out in a GH-3-type rolling oven through hot rolling at an appointed temperature $(160,170,180,190,200,210,220,230,240,250$ and $260^{\circ} \mathrm{C}$ ) for $16 \mathrm{~h}$. Fluid property tests were performed before and after the thermal aging tests.

The rheological properties of the treated water-based drilling fluids were measured using a DNN-Z6 type six-speed rotating viscometer (Qingdao Haitongda Special Instrument Co., Ltd., China). Rheological parameters such as apparent viscosity (AV), plastic viscosity (PV) and yield point (YP) can be calculated from 300 and $600 \mathrm{rpm}$ readings $\left(\Phi_{300}\right.$ and $\left.\Phi_{600}\right)$ as per eqn (1)-(3).

$$
\begin{gathered}
\mathrm{AV}=0.5 \Phi_{600}(\mathrm{mPa} \mathrm{s}) \\
\mathrm{PV}=\Phi_{600}-\Phi_{300}(\mathrm{mPa} \mathrm{s}) \\
\mathrm{YP}=0.5\left(2 \Phi_{300}-\Phi_{600}\right)(\mathrm{Pa})
\end{gathered}
$$

The ratio of YP and PV (RYP) is an important rheological parameter. It is a measure of the shear thinning behavior of drilling fluids. A high ratio indicates outstanding carrying efficiency and lower settling velocity of cuttings. If the gauge hole is not maintained and the diameter of the borehole increases, a fluid with a high RYP is desirable..$^{30,31}$

The $\mathrm{FL}_{\mathrm{API}}$ of water-based drilling fluid was measured using a ZNZ-D3 type medium-pressure filtration apparatus (Qingdao Haitongda Special Instrument Co., Ltd., China). The hightemperature/high-pressure filtrate volume $\left(\mathrm{FL}_{\mathrm{HTHP}}\right)$ was determined with a GGS42 type high-temperature/high-pressure filtration apparatus (Qingdao Jiaonan Tongchun Machinery Petroleum instrument Ltd., China). $\mathrm{FL}_{\mathrm{API}}$ and $\mathrm{FL}_{\mathrm{HTHP}}$ were loaded on the filter press equipped with a filter paper under a fixed pressure of $0.7 \mathrm{MPa}$ and $3.5 \mathrm{MPa}$, respectively. The results were recorded after $30 \mathrm{~min}$, as recommended by American Petroleum Institute (API) specifications. 
In a drilling operation, during the process of drilling fluid being mechanically sheared by the mud pump, impacting the bottom hole and scouring the well wall, some chemical bonds of the polymer in the fluid become broken, negatively impacting the performance of the drilling fluid. Agents with good performance sustainability can not only reduce the material consumption, but also help to reduce the maintenance frequency of the drilling fluid. Therefore, it is necessary to evaluate the performance sustainability of agents.

First, the Na-MMT/PAAN, Na-MMT/PAAND and Na-MMT/ PAANS systems were stirred at a speed of $10000 \mathrm{rpm}$ for 20 min using a TD250-2-type high-speed mechanical blender (Beijing Kelishi Petroleum instrument, China) to simulate the process of high-speed shear damage to the internal structure of the drilling fluid during injection of the mud pump, and then to determine its $\mathrm{FL}_{\mathrm{API}}$ and $\mathrm{FL}_{\mathrm{HTHP}}$. Second, the Na-MMT/PAAN, Na-MMT/PAAND and Na-MMT/PAANS systems were placed in a GH-3-type rolling oven where they underwent hot rolling at appointed temperatures for $4 \mathrm{~h}$ to simulate the effect of the high temperature at the bottom of the well on the composition of the drilling fluid. The Na-MMT/PAAN, Na-MMT/PAAND and NaMMT/PAANS systems were stirred at a speed of $10000 \mathrm{rpm}$ for 20 min again, and then $\mathrm{FL}_{\mathrm{API}}$ and $\mathrm{FL}_{\mathrm{HTHP}}$ were determined. The performance sustainability of the drilling fluid during the whole circulation process in drilling operation was evaluated by repeating step 2 .

\section{Mechanism analysis}

The amount of PAAN, PAAND and PAANS adsorbed onto NaMMT in water-based drilling fluid was measured using Vario TOC total organic carbon analysis (Elementar Analysensysteme $\mathrm{GmbH}$, Germany) using thermal filtration. This was done following the procedure previously described by Chu et al. ${ }^{32}$ The method of thermal filtration can accurately reflect the adsorption amount of the polymer molecules under high temperature conditions.

The particle size distribution was determined using a Mastersizer 3000 ultra-high speed intelligent laser diffraction particle size analyzer (LPSA, Malvern Instruments Ltd., Britain).

The fresh filter cake from the fluid loss test was cut horizontally into two equal halves. The surface of a fragment that was inside the filter cake was investigated using a Quanta 450 environmental scanning electron microscope (ESEM, FEI Co., USA) with an Everhart-Thornley secondary electron detector (accelerating potential $25.0 \mathrm{kV}$ at $3.0{ }^{\circ} \mathrm{C}$ and $6.8 \mathrm{mbar}$ ). The ESEM allows for the viewing of the wet filter cakes in their original and unaltered state.

\section{Results and discussion}

\section{Characterization}

The ${ }^{1} \mathrm{H}$ NMR spectra of PAAN, PAAND and PAANS are shown in Fig. 3. In Fig. 3, several characteristic peaks of different monomers can be seen in the spectra of PAAN, PAAND and PAANS. For PAAN, a peak for $-\mathrm{CH}_{3}$ in AMPS can be seen at $1.52 \mathrm{ppm}$. Peaks for $-\mathrm{CH}_{2}^{-}$ $\mathrm{CH}-\mathrm{CO}-$ and $-\mathrm{CH}-\mathrm{CO}-$ in the backbone of the polymer are present

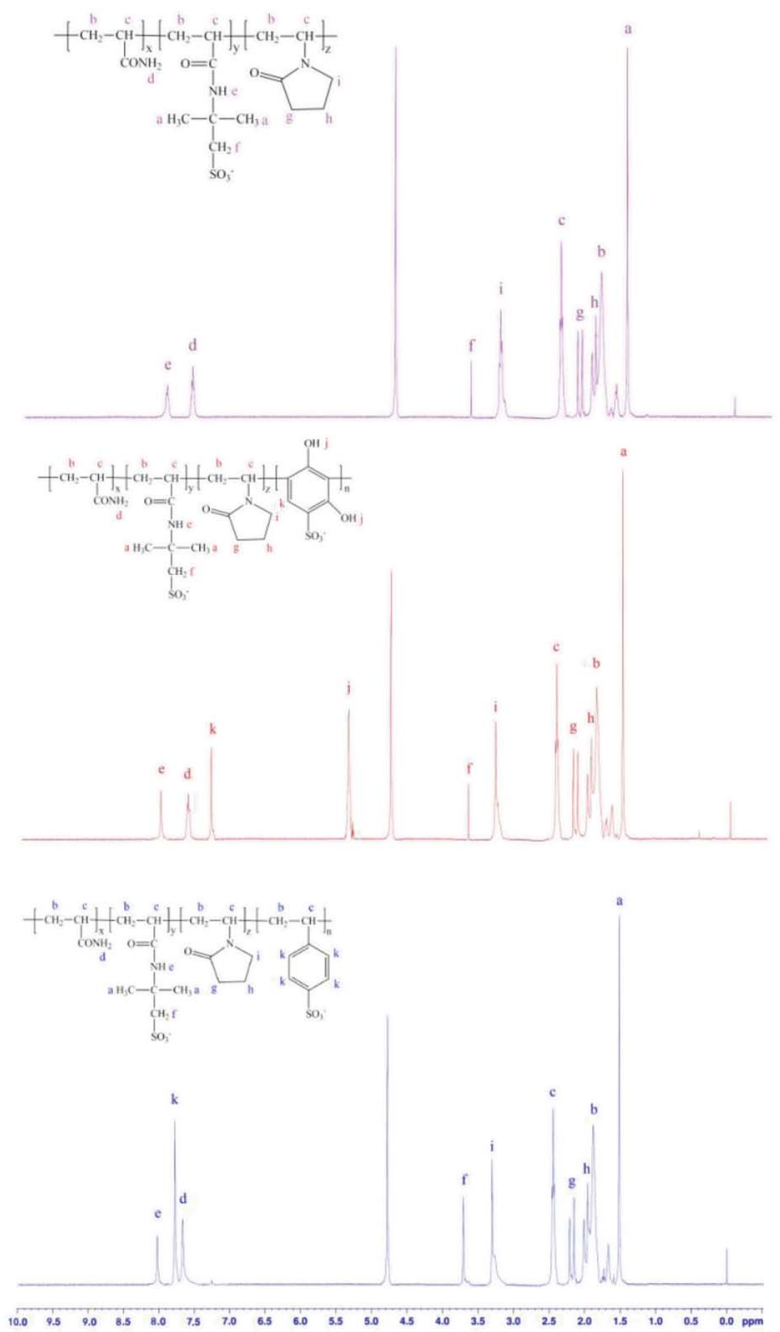

Fig. $3{ }^{1} \mathrm{H}$ NMR spectra of PAAN, PAAND and PAANS.

in the regions of 1.68-2.08 ppm and 2.43-3.23 ppm, respectively. Peaks for-CO-NH $\mathrm{N}_{2}$ in AM and -CO-NH- in AMPS can be observed at 7.66 and $8.03 \mathrm{ppm}$, respectively. The peak at $3.71 \mathrm{ppm}$ is for $-\mathrm{CH}_{2}-\mathrm{SO}_{3}{ }^{-}$in AMPS. Peaks for the ring structure protons of NVP are present at 1.91, 2.18 and $3.29 \mathrm{ppm}$. Compared with PAAN, typical chemical-shift values of protons in PAAND for -OH and phenyl of DHBS were observed at $5.35 \mathrm{ppm}$ and $7.30 \mathrm{ppm}$, respectively, and a typical chemical-shift value of protons in PAANS for phenyl of SSS was observed at $7.78 \mathrm{ppm}$. The ${ }^{1} \mathrm{H}$ NMR spectrum affirmed the successful copolymerization of the monomers.

The weight-average molecular weight $\left(M_{\mathrm{w}}\right)$ and numberaverage molecular weight $\left(M_{\mathrm{n}}\right)$ were obtained from SLS analysis in $0.1 \mathrm{~mol} \mathrm{~L}^{-1} \mathrm{NaCl}$ solution. The composition, $M_{\mathrm{w}}$ and $M_{\mathrm{n}}$ of PAAN, PAAND and PAANS are shown in Table 1 . Table 1 illustrates that the polymer molar composition of DHBS in PAAND was lower than the corresponding monomer feed composition, but that of SSS in PAANS was higher than the corresponding monomer feed composition, which was probably due to the reactivity ratio difference of DHBS compared to other monomers. PAAN, PAAND and PAANS have smaller $M_{\mathrm{w}}$ and $M_{\mathrm{n}}$ values, indicating that DHBS and SSS have an insignificant effect on molecular weight. 
Table 1 Composition and molecular weight of PAAN, PAAND and PAANS

\begin{tabular}{|c|c|c|c|c|c|c|c|c|}
\hline \multirow[b]{2}{*}{ Sample } & \multirow{2}{*}{$\begin{array}{l}\text { Feed molar composition } \\
\text { (AM/AMPS/NVP/DHBS) } \\
\text { or (AM/AMPS/NVP/SSS) }\end{array}$} & \multicolumn{4}{|c|}{ Elemental composition (\%) } & \multirow{2}{*}{$\begin{array}{l}\text { Polymer molar composition } \\
\text { (AM/AMPS/NVP/DHBS) } \\
\text { or (AM/AMPS/NVP/SSS) }\end{array}$} & \multirow[b]{2}{*}{$M_{\mathrm{w}}\left(\times 10^{4}, \mathrm{~g} \mathrm{~mol}^{-1}\right)$} & \multirow[b]{2}{*}{$M_{\mathrm{n}}\left(\times 10^{4}, \mathrm{~g} \mathrm{~mol}^{-1}\right)$} \\
\hline & & $\mathrm{C}$ & $\mathrm{N}$ & $\mathrm{O}$ & $\mathrm{S}$ & & & \\
\hline PAAN & $60: 20: 12: 0$ & 46.2925 & 12.4509 & 24.0542 & 6.5682 & $58.50: 21.20: 12.30: 0$ & 7.9931 & 8.1321 \\
\hline PAAND & $60: 20: 12: 8$ & 44.4721 & 10.6686 & 25.3449 & 7.3727 & $55.72: 23.63: 14.55: 6.10$ & 7.7600 & 7.8540 \\
\hline PAANS & $60: 20: 12: 8$ & 46.3432 & 10.5410 & 23.9306 & 7.9465 & $57.39: 21.02: 12.63: 8.96$ & 8.0564 & 8.1719 \\
\hline
\end{tabular}

In order to investigate the influence of the percentage of DHBS in PAAND and that of SSS in PAANS on the rheological and filtration properties in water-based drilling fluid, a series of polymers (PAAND and PAANS) containing rigid monomers (DHBS and SSS) with different ratios were synthesized using a similar procedure. The products are abbreviated as PAAND-1 to PAAND-6 and PAANS-1 to PAANS-6, respectively. The main compositions are listed in Table 2.

\section{Rheological properties}

Table 2 shows the effect of PAAN, PAAND and PAANS concentration on the rheological characteristics of the water-based drilling fluid after thermal aging tests at $200{ }^{\circ} \mathrm{C}$ and $240{ }^{\circ} \mathrm{C}$. After adding PAAN, AV, PV and YP of the Na-MMT-based drilling fluid increase. Compared with PAAN, the rheological parameter values of the Na-MMT-based drilling fluids containing PAAND or PAANS were much higher after treatment at the same thermal aging temperature, although $M_{\mathrm{w}}$ and $M_{\mathrm{n}}$ of PAAND and PAANS were similar to that of PAAN. The rheological parameter values of PAAND and PAANS were similar after thermal aging test at $200{ }^{\circ} \mathrm{C}$, but differentiated when the thermal aging temperature reached $240^{\circ} \mathrm{C}$. When the concentration was $2.0 \%, \mathrm{AV}, \mathrm{PV}$ and YP of the Na-MMT/PAAND system were $18.0 \mathrm{mP} \mathrm{s}, 12.0 \mathrm{mP}$ s and 6.0 Pa, respectively, after thermal aging tests at $240{ }^{\circ} \mathrm{C}$. Under the same conditions, AV, PV and YP of the Na-MMT/PAAN system were $7.0 \mathrm{mP} \mathrm{s}, 5.0 \mathrm{mP}$ s and $2.0 \mathrm{~Pa}$, respectively, and $\mathrm{AV}, \mathrm{PV}$ and $\mathrm{YP}$ of the Na-MMT/PAANS system were $8.5 \mathrm{mP}$ s, 6.0 $\mathrm{mP}$ s and $2.5 \mathrm{~Pa}$, respectively. The results indicate the Na-MMTbased drilling fluid treated with PAAND has excellent rheological properties. Hence, it is reasonable to believe that synthetic polymers with rigid monomers in their backbone have higher temperature resistance than those with rigid monomers in their side chains.

When the concentration was $2.0 \%$, the Na-MMT-based drilling fluids treated with PAAN, PAAND and PAANS were hot rolled at different temperatures for $16 \mathrm{~h}$, respectively. Rheological parameters were measured after the thermal aging tests (Table 3). The results are shown in Table 4.

The information in Table 4 can be summarized as follows. First, the rheological parameters of the Na-MMT/PAAN, NaMMT/PAAND and Na-MMT/PAANS systems gradually deceased with increasing temperature from $160{ }^{\circ} \mathrm{C}$ to $260{ }^{\circ} \mathrm{C}$. Second, compared with PAAN, the rheological parameters of the NaMMT-based drilling fluids treated with PAAND or PAANS were much higher at the same temperature, meaning that PAAND and PAANS have excellent thermal stability. Third, the rheological parameters of PAAND and PAANS were similar when the thermal aging temperature was less than $200{ }^{\circ} \mathrm{C}$, but when the thermal aging temperature exceeded $200{ }^{\circ} \mathrm{C}$, the rheological parameters of PAAND were significantly higher than those of PAANS. Additionally, when the thermal aging temperature was raised to $260^{\circ} \mathrm{C}, \mathrm{AV}, \mathrm{PV}$ and $\mathrm{YP}$ of the Na-MMT/PAAND system were $6.5 \mathrm{mP} \mathrm{s}, 5.0 \mathrm{mP} \mathrm{s}$ and $1.5 \mathrm{~Pa}$, and those of the Na-MMT/ PAANS system were $3.0 \mathrm{mP} \mathrm{s}, 2.0 \mathrm{mP}$ s and $1.0 \mathrm{~Pa}$, respectively, indicating that the synthetic polymer modified with rigid monomers as a fluid loss additive may have failed due to thermal degradation. This phenomenon can be explained as follows. The rigid monomer distributed in the backbone or side chain of the molecule can effectively reduce the vibration degree of freedom of the molecular chain; that is, the rigid monomer reduces the movement velocity of the molecule at high

Table 2 Composition of PAAND- 1 to PAAND- 6 and PAANS- 1 to PAANS- 6

\begin{tabular}{lll}
\hline & $\begin{array}{l}\text { Feed molar composition } \\
\text { (AM/AMPS/NVP/DHBS) or (AM/AMPS/NVP/SSS) }\end{array}$ & $\begin{array}{l}\text { Polymer molar composition (AM/AMPS/NVP/DHBS) } \\
\text { or (AM/AMPS/NVP/SSS) }\end{array}$ \\
\hline PAAND-1 & $60: 20: 12: 4$ & $59.28: 24.02: 13.74: 2.96$ \\
PAAND-2 & $60: 20: 12: 6$ & $56.96: 23.83: 14.17: 5.04$ \\
PAAND-3 & $60: 20: 12: 10$ & $58.74: 21.11: 11.97: 8.18$ \\
PAAND-4 & $60: 20: 12: 12$ & $57.91: 20.52: 11.44: 10.13$ \\
PAAND-5 & $60: 20: 12: 14$ & $56.32: 20.20: 11.36: 12.12$ \\
PAAND-6 & $60: 20: 12: 16$ & $55.59: 20.01: 11.02: 13.38$ \\
PAANS-1 & $60: 20: 12: 4$ & $63.21: 20.51: 12.11: 4.17$ \\
PAANS-2 & $60: 20: 12: 6$ & $60.63: 21.05: 12.14: 6.18$ \\
PAANS-3 & $60: 20: 12: 10$ & $57.69: 20.75: 12.00: 9.56$ \\
PAANS-4 & $60: 20: 12: 12$ & $56.21: 20.36: 11.85: 11.57$ \\
PAANS-5 & $60: 20: 12: 14$ & $54.75: 20.14: 11.61: 13.50$ \\
PAANS-6 & $60: 20: 12: 16$ & $53.07: 20.00: 11.54: 15.39$
\end{tabular}


Table 3 Effect of concentration on the rheological properties of PAAN, PAAND and PAANS in Na-MMT-based drilling fluid after thermal aging tests

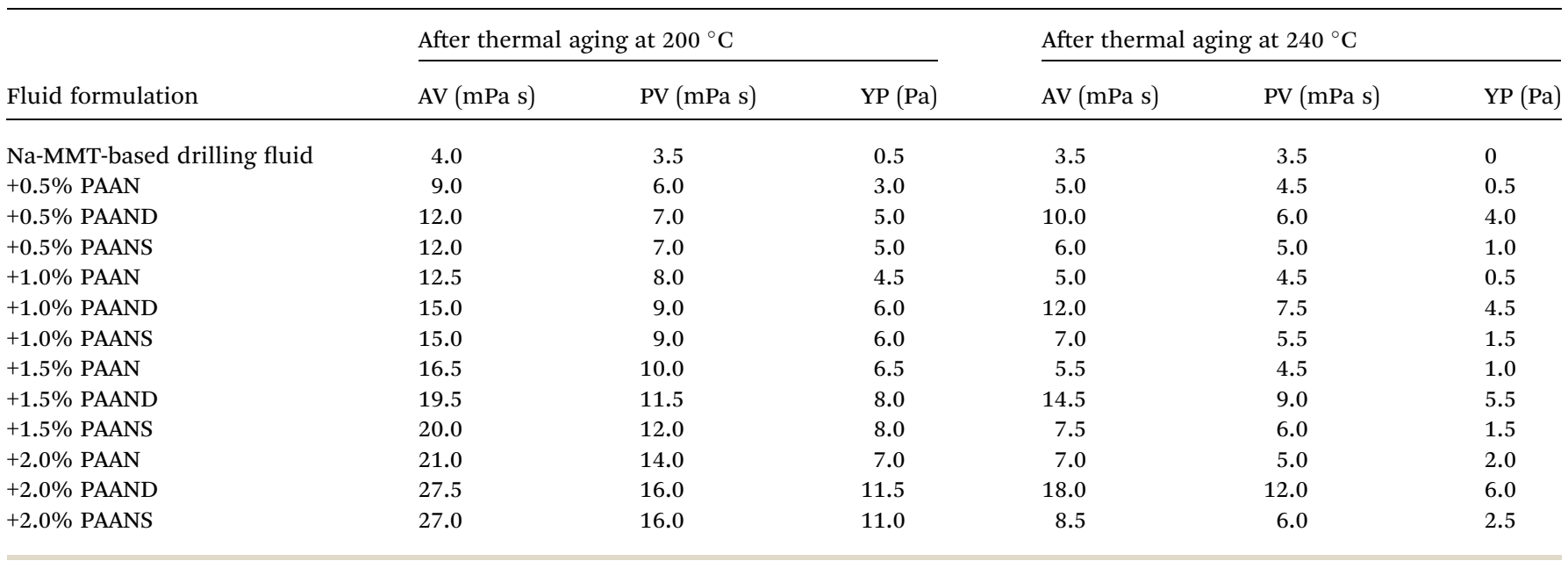

Table 4 Effect of thermal aging temperature on the rheological properties of PAAN, PAAND and PAANS in Na-MMT-based drilling fluid

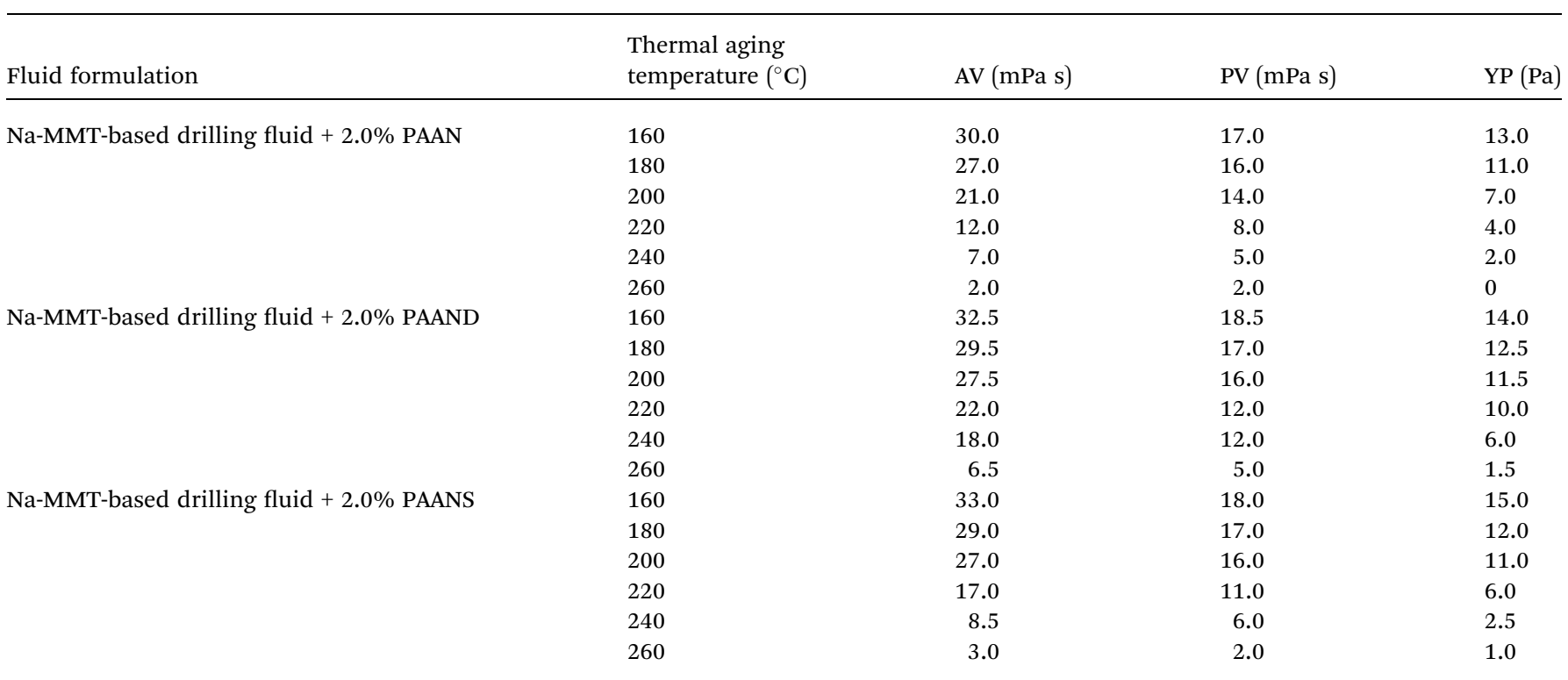

temperature and reduces the incidence of the unwinding of the polymer. The interaction force between polymer molecules and between the polymer and Na-MMT is improved, and the stability of the 3D network structure of the drilling fluid is improved, which makes the polymer show strong thermal stability in water-based drilling fluid. Compared with the modification of the molecular side chain by rigid monomers, adding rigid monomers to the backbone can reduce the thermal movement of the molecule at high temperature to a certain extent, thus leading to better high temperature resistance in water-based drilling fluid.

The influence of the percentage of rigid monomers in the polymer molecule on the rheological properties of the series of polymers in Na-MMT-based drilling fluid (at a concentration of $2.0 \%$ ) after thermal aging tests at $200{ }^{\circ} \mathrm{C}$ and $240{ }^{\circ} \mathrm{C}$ was investigated, and the results are shown in Table 5. It is apparent that the rheological parameters gradually increase with increasing rigid monomer percentage in the polymer after thermal aging tests at $200{ }^{\circ} \mathrm{C}$. By comparing the rheological parameters of the series of polymers in Na-MMT-based drilling fluid, it was found that there are no significant differences in introducing rigid monomers into the backbone compared to the side chains in improving the rheological stability of waterbased drilling fluid. When the thermal aging temperature reached $240{ }^{\circ} \mathrm{C}$, for the PAAND-type series of polymers, the rheological parameters slightly increased with the increase in the percentage of rigid monomer, and were significantly higher than that of PAAN, showing good rheological stability. However, for the PAANS-type series of polymers, the rheological parameters were similar to those of PAAN, indicating that if rigid monomers are introduced into the side chain, the stability of improving the rheological properties of water-based drilling 
Table 5 Effect of rigid monomer percentage on rheological properties in Na-MMT drilling fluid after thermal aging tests

\begin{tabular}{|c|c|c|c|c|c|c|}
\hline \multirow[b]{2}{*}{ Sample } & \multicolumn{3}{|c|}{ After thermal aging at $200{ }^{\circ} \mathrm{C}$} & \multicolumn{3}{|c|}{ After thermal aging at $240^{\circ} \mathrm{C}$} \\
\hline & $\mathrm{AV}(\mathrm{mPa} \mathrm{s})$ & $\mathrm{PV}(\mathrm{mPa} s)$ & YP (Pa) & $\mathrm{AV}(\mathrm{mPa} \mathrm{s})$ & $\mathrm{PV}(\mathrm{mPa} \mathrm{s})$ & $\mathrm{YP}(\mathrm{Pa})$ \\
\hline PAAN & 21.0 & 14.0 & 7.0 & 7.0 & 5.0 & 2.0 \\
\hline $\begin{array}{l}\text { PAAND- } \\
1\end{array}$ & 21.5 & 14.5 & 7.0 & 7.5 & 5.0 & 2.5 \\
\hline $\begin{array}{l}\text { PAAND- } \\
2\end{array}$ & 23.5 & 15.0 & 8.5 & 11.0 & 7.0 & 4.0 \\
\hline PAAND & 27.5 & 16.0 & 11.5 & 18.0 & 12.0 & 6.0 \\
\hline $\begin{array}{l}\text { PAAND- } \\
3\end{array}$ & 29.5 & 17.5 & 12.0 & 19.0 & 12.5 & 6.5 \\
\hline $\begin{array}{l}\text { PAAND- } \\
4\end{array}$ & 30.0 & 18.0 & 12.0 & 19.5 & 12.5 & 7.0 \\
\hline $\begin{array}{l}\text { PAAND- } \\
5\end{array}$ & 31.0 & 18.5 & 12.5 & 19.5 & 12.5 & 7.0 \\
\hline $\begin{array}{l}\text { PAAND- } \\
6\end{array}$ & 32.0 & 19.0 & 13.0 & 20.5 & 13.0 & 7.5 \\
\hline PAANS-1 & 21.5 & 14.5 & 7.0 & 7.0 & 5.0 & 2.0 \\
\hline PAANS-2 & 23.0 & 15.0 & 8.0 & 8.0 & 5.5 & 2.5 \\
\hline PAANS & 27.0 & 16.0 & 11.0 & 8.5 & 6.0 & 2.5 \\
\hline PAANS-3 & 29.0 & 17.0 & 12.0 & 10.0 & 7.0 & 3.0 \\
\hline PAANS-4 & 29.5 & 17.5 & 12.0 & 10.0 & 7.0 & 3.0 \\
\hline PAANS-5 & 29.5 & 17.5 & 12.0 & 10.0 & 7.0 & 3.0 \\
\hline PAANS-6 & 30.5 & 18.0 & 12.5 & 10.5 & 7.5 & 3.0 \\
\hline
\end{tabular}

fluid is not significant. This is mainly due to the introduction of rigid monomers, especially their introduction into the backbone, which is more beneficial to improving the thermal stability of a polymeric fluid loss additive.

\section{Filtration properties}

A series of filtration tests for PAAN, PAAND and PAANS were conducted in Na-MMT-based drilling fluid after thermal aging at $200{ }^{\circ} \mathrm{C}$ for $16 \mathrm{~h}$. In Fig. 4 and 5, we can see that with the increase of the concentration, the $\mathrm{FL}_{\mathrm{API}}$ and $\mathrm{FL}_{\mathrm{HTHP}}$ of the NaMMT/PAAN, Na-MMT/PAAND and Na-MMT/PAANS systems decreased gradually, and when the concentration was higher

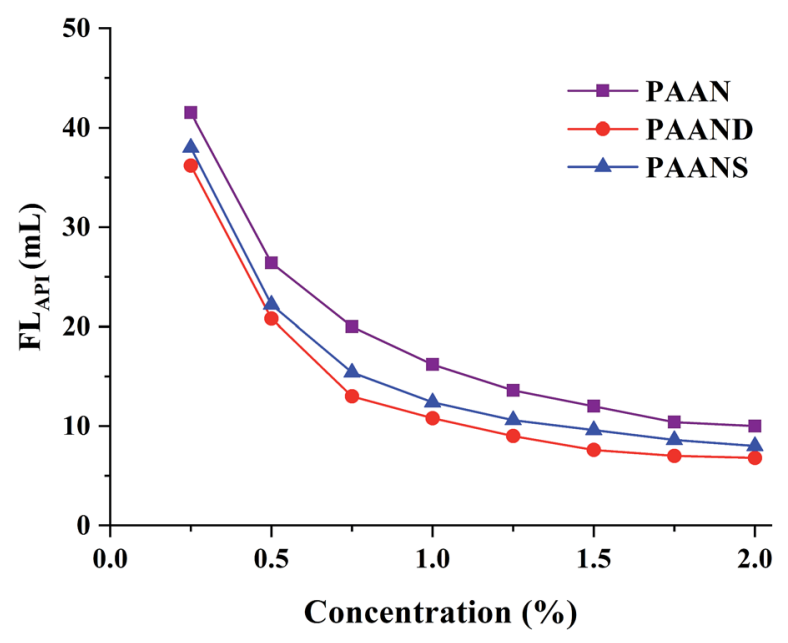

Fig. 4 Effect of concentration on $\mathrm{FL}_{\mathrm{API}}$ of PAAN, PAAND and PAANS in $\mathrm{Na}-\mathrm{MMT}$-based drilling fluid after thermal aging tests at $200^{\circ} \mathrm{C}$.

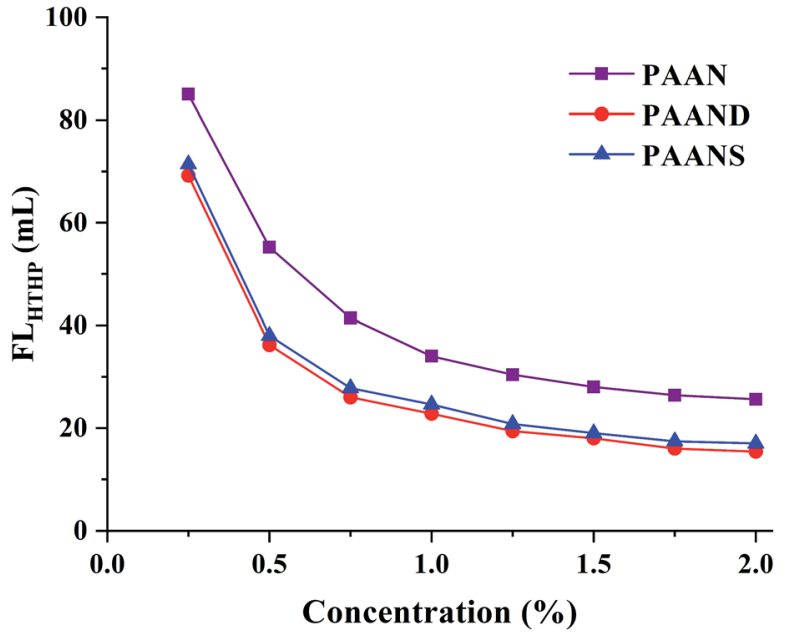

Fig. 5 Effect of concentration on $\mathrm{FL}_{\mathrm{HTHP}}$ of PAAN, PAAND and PAANS in Na-MMT-based drilling fluid after thermal aging tests at $200^{\circ} \mathrm{C}$.

than $1.5 \%$, the decreasing trend of drilling fluid filtration slowed down. PAAND showed the best performance in controlling the $\mathrm{FL}_{\mathrm{API}}$ and $\mathrm{FL}_{\mathrm{HTHP}}$. When the concentration ranged from $0.25 \%$ to $2.0 \%, \mathrm{FL}_{\mathrm{API}}$ of the Na-MMT/PAAND system decreased from $36.2 \mathrm{~mL}$ to $6.8 \mathrm{~mL}$, and $\mathrm{FL}_{\mathrm{HTHP}}$ of the Na-MMT/PAAND system decreased from $69.2 \mathrm{~mL}$ to $15.4 \mathrm{~mL}$.

At the same concentration, the $\mathrm{FL}_{\mathrm{API}}$ and $\mathrm{FL}_{\mathrm{HTHP}}$ of the NaMMT/PAAND system were slightly lower than those of the NaMMT/PAANS system, indicating that it is more advantageous to improve the filtration performance by introducing rigid monomers in the backbone of the polymer molecules than in the side chains. Compared with PAAN and PAANS, the combination formed between PAAND and clay has stronger stability, which thickens the hydration film on the surface of clay particles and prevents the aggregation of clay particles into large particles due to collision, thus helping to maintain the content of fine particles in the drilling fluid, forming a mud cake with low permeability and reducing filtration loss.

The effect of temperature on $\mathrm{FL}_{\mathrm{API}}$ and $\mathrm{FL}_{\mathrm{HTHP}}$ of $2.0 \%$ PAAN, PAAND and PAANS in Na-MMT-based drilling fluid was investigated after thermal aging tests, and the results are shown in Fig. 6 and 7. With the increase of temperature, the $\mathrm{FL}_{\mathrm{API}}$ and $\mathrm{FL}_{\mathrm{HTHP}}$ of Na-MMT/PAAN, Na-MMT/PAAND and Na-MMT/ PAANS systems increased significantly. At the same temperature, the order of controlling $\mathrm{FL}_{\mathrm{API}}$ and $\mathrm{FL}_{\mathrm{HTHP}}$ was PAAND > PAANS > PAAN in Na-MMT/PAANS-based drilling fluid. When the temperature was higher than $200{ }^{\circ} \mathrm{C}$ and $220^{\circ} \mathrm{C}$, the filtration of the Na-MMT/PAAN and Na-MMT/PAANS systems was out of control, respectively. In contrast, the $\mathrm{FL}_{\mathrm{API}}$ and $\mathrm{FL}_{\mathrm{HTHP}}$ of the Na-MMT/PAAND system were $10.0 \mathrm{~mL}$ and $22.0 \mathrm{~mL}$ after thermal aging tests at $230{ }^{\circ} \mathrm{C}$, and when the thermal aging temperature rose to $240{ }^{\circ} \mathrm{C}$, the $\mathrm{FL}_{\mathrm{API}}$ and $\mathrm{FL}_{\mathrm{HTHP}}$ of Na-MMTbased drilling fluid treated with PAAND increased to $12.0 \mathrm{~mL}$ and $30.0 \mathrm{~mL}$, respectively, which was still within the range of control. There is sufficient experimental evidence to prove that the temperature resistance of PAAND as a fluid loss additive can reach $240{ }^{\circ} \mathrm{C}$. Therefore, based on the above results, it is clear that the introduction of rigid monomers, especially in the 


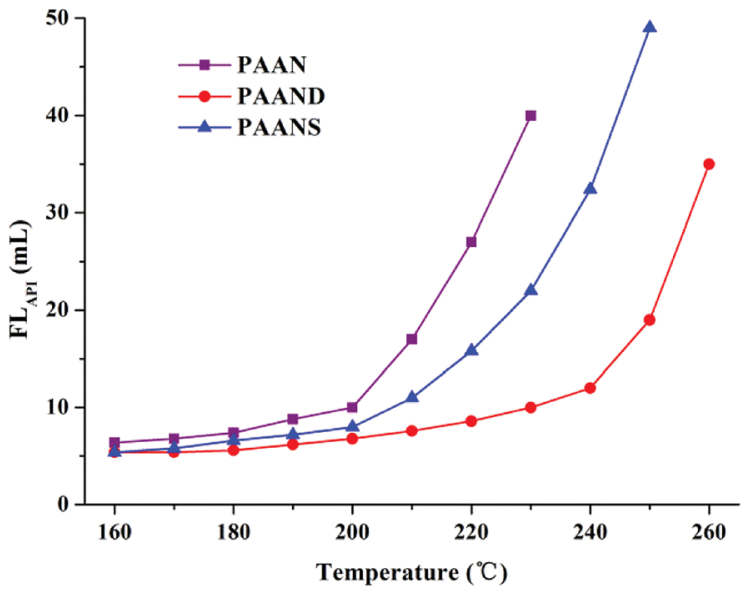

Fig. 6 Effect of temperature on $\mathrm{FL}_{\mathrm{API}}$ of PAAN, PAAND and PAANS in $\mathrm{Na-MMT-based} \mathrm{drilling} \mathrm{fluid} \mathrm{after} \mathrm{thermal} \mathrm{aging} \mathrm{tests.}$

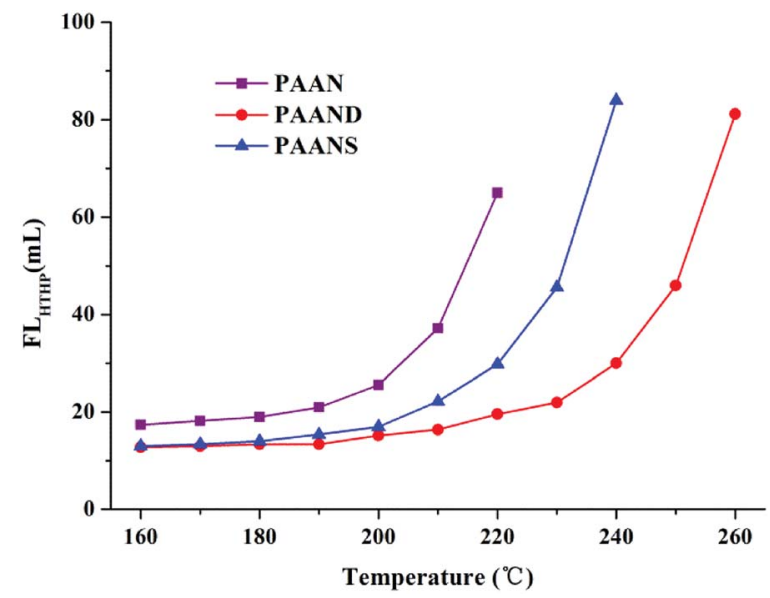

Fig. 7 Effect of temperature on $\mathrm{FL}_{\mathrm{HTHP}}$ of PAAN, PAAND and PAANS in Na-MMT-based drilling fluid after thermal aging tests.

backbone, can effectively improve the temperature resistance of polymeric fluid loss additives.

Fig. 8a and b illustrate the $\mathrm{FL}_{\mathrm{API}}$ curves of $2.0 \%$ PAAND-type and PAANS-type series of polymers in Na-MMT-based drilling fluid after thermal aging tests at $200^{\circ} \mathrm{C}$ and $240{ }^{\circ} \mathrm{C}$, respectively. When the thermal aging temperature was $200{ }^{\circ} \mathrm{C}$, the $\mathrm{FL}_{\mathrm{API}}$ of PAADN and PAANS in Na-MMT-based drilling fluid was significantly affected by the percentage of rigid monomers. When the percentage of rigid monomers in polymer molecules was 6.0$8.0 \%$, the $\mathrm{FL}_{\mathrm{API}}$ was in a low range. When the thermal aging temperature reached $240{ }^{\circ} \mathrm{C}$, the $\mathrm{FL}_{\mathrm{API}}$ of the PAAND-type series of polymers was significantly affected by the percentage of rigid monomers compared with that of the PAANS-type series of polymers. As indicated in Fig. 9a and b, which illustrate the $\mathrm{FL}_{\mathrm{HTHP}}$ curves of $2.0 \%$ PAAND-type and PAANS-type polymers in Na-MMT-based drilling fluid after thermal aging tests at $200{ }^{\circ} \mathrm{C}$ and $240{ }^{\circ} \mathrm{C}$, the variation trend of $\mathrm{FL}_{\mathrm{HTHP}}$ with the percentage of rigid monomers is similar to that of $\mathrm{FL}_{\mathrm{API}}$ with the percentage of rigid monomers. The polymeric fluid loss additive with rigid monomers in the polymer molecules can improve the filtration (a)

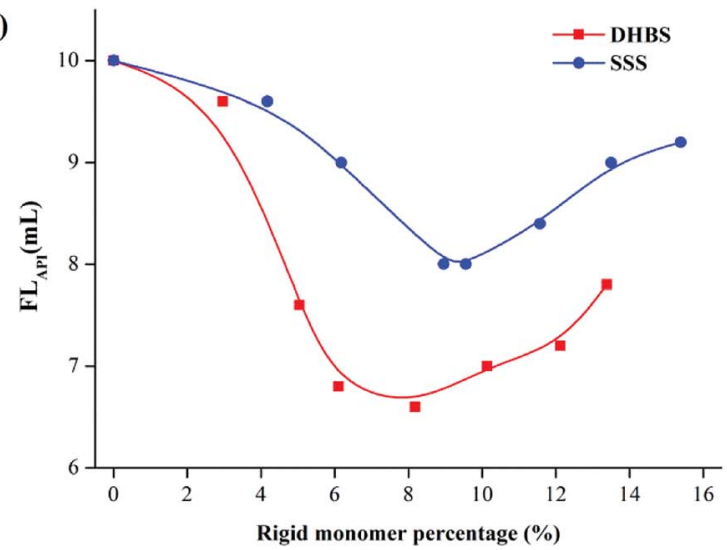

(b)

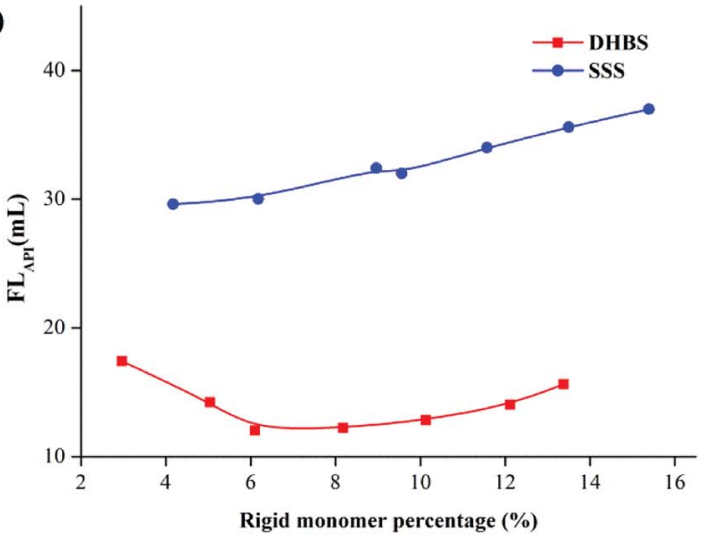

Fig. 8 Effect of rigid monomer percentage in polymer molecules on $\mathrm{FL}_{\text {API }}$ in $\mathrm{Na}$-MMT drilling fluid after thermal aging tests at (a) $200^{\circ} \mathrm{C}$ and (b) $240{ }^{\circ} \mathrm{C}$.

properties of water-based drilling fluid, especially when rigid monomers are introduced into the backbone. However, the introduction ratio must be appropriate. An excessive ratio will reduce the percentage of other functional groups and affect the performance of the fluid loss additive.

\section{Performance sustainability}

Fig. 10 and 11 illustrate the effects of the total thermal aging time on the $\mathrm{FL}_{\mathrm{API}}$ and $\mathrm{FL}_{\mathrm{HTHP}}$ of PAAN, PAAND and PAANS in Na-MMT-based drilling fluid. As indicated in Fig. 10 and 11, with the increase of the total thermal aging time, the $\mathrm{FL}_{\mathrm{API}}$ and $\mathrm{FL}_{\mathrm{HTHP}}$ of Na-MMT/PAAN, Na-MMT/PAAND and Na-MMT/ PAANS increased significantly, indicating that shear forces and high temperature have certain negative effects on the filtration performance of the polymeric fluid loss additives. The $\mathrm{FL}_{\mathrm{API}}$ of PAAN, PAAND and PAANS increased from $1.6 \mathrm{~mL}$ before thermal aging to $18.8 \mathrm{~mL}, 10.6 \mathrm{~mL}$ and $11.6 \mathrm{~mL}$ after $24 \mathrm{~h}$ of thermal aging, respectively. The $\mathrm{FL}_{\mathrm{HTHP}}$ of PAAN, PAAND and PAANS increased from $8.6 \mathrm{~mL}$ before the thermal aging tests to $48.8 \mathrm{~mL}, 24.6 \mathrm{~mL}$ and $26.6 \mathrm{~mL}$, respectively, when the total thermal aging time was $24 \mathrm{~h}$. Moreover, at the same total thermal aging time, the control order of $\mathrm{FL}_{\mathrm{API}}$ and $\mathrm{FL}_{\mathrm{HTHP}}$ was PAAND $>$ PAANS $>$ PAAN in drilling fluid, indicating that the introduction of rigid monomers in the molecular chain, especially the polymer backbone, is helpful for improving the 
(a)

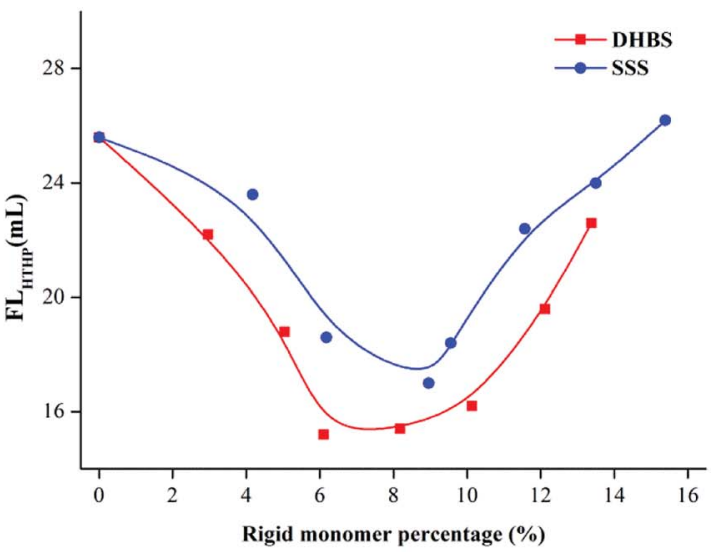

(b)

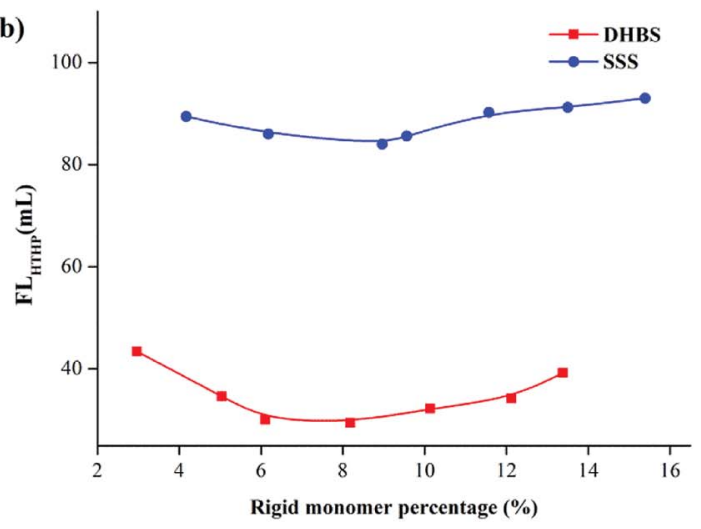

Fig. 9 Effect of rigid monomer percentage in polymer molecules on FL $L_{\text {HTP }}$ in Na-MMT drilling fluid after thermal aging tests at (a) $200{ }^{\circ} \mathrm{C}$ and (b) $240{ }^{\circ} \mathrm{C}$.

performance sustainability of polymeric fluid loss additives. This may be because the introduction of rigid monomers in the molecular chain can hinder the rotation of chemical bonds and conformational changes, thus reducing the thermal motion speed of the molecular chain and increasing its stability at high temperature. In particular, the introduction of rigid monomers into the backbone can effectively improve its activity at high

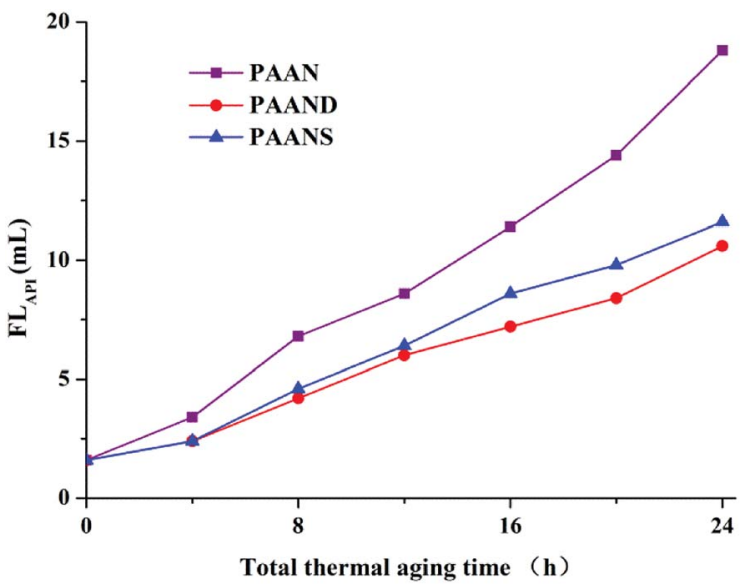

Fig. $10 \mathrm{FL}_{\mathrm{API}}$ of PAAN, PAAND and PAANS in Na-MMT-based drilling fluid after multiple shearing and thermal aging tests.

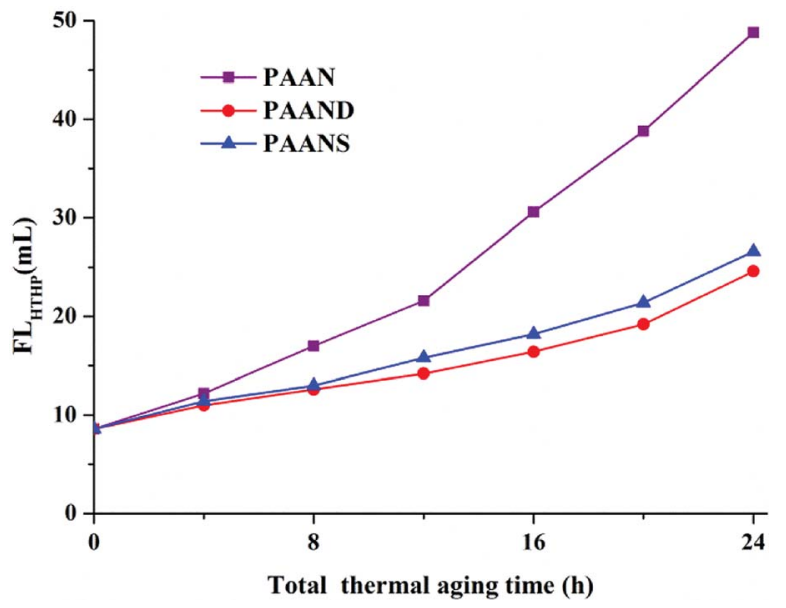

Fig. 11 FL $L_{\text {HTHP }}$ of PAAN, PAAND and PAANS in Na-MMT-based drilling fluid after multiple shearing and thermal aging tests.

temperature, increase the shear and high temperature resistance of the molecular chain, and achieve the goal of performance sustainability.

\section{Mechanism analysis}

The adsorption capacities of PAAN, PAAND and PAANS at different temperatures were measured to investigate the effect of rigid monomers on the improvement of interaction intensity between Na-MMT and the polymers. The dynamic adsorption curves of PAAN, PAAND and PAANS at $160{ }^{\circ} \mathrm{C}$ are shown in Fig. 12.

As indicated in Fig. 12, the adsorption reaction of PAAN, PAAND and PAANS in Na-MMT-based drilling fluid reached equilibrium after $30 \mathrm{~min}$, and the equilibrium adsorption concentration was $18.06 \mathrm{mg} \mathrm{g}^{-1}$ clay particles, $21.53 \mathrm{mg} \mathrm{g}^{-1}$ clay particles and $20.66 \mathrm{mg} \mathrm{g}^{-1}$ clay particles, respectively. It was clearly found that the adsorbed amounts of PAAND and PAANS were similar but were obviously higher than that of PAAN at any moment, meaning that the rigid monomer can promote polymer adsorption on Na-MMT to a certain extent.

To further investigate the effect of rigid monomers in polymers used as fluid loss additives, especially at high temperature, a comparative test between PAAN, PAAND and PAANS was carried out in Na-MMT/PAAN, Na-MMT/PAAND and Na-MMT/ PAANS systems at a concentration of $1.0 \mathrm{wt} \%$ after thermal aging tests for $16 \mathrm{~h}$. The adsorption curves of PAANS and PAAN at temperatures from $160{ }^{\circ} \mathrm{C}$ to $260{ }^{\circ} \mathrm{C}$ are shown in Fig. 13 .

As indicated in Fig. 13, the adsorbed amount of PAAN, PAAND and PAANS in Na-MMT-based drilling fluid decreased with increasing temperature. The adsorbed amount of PAAND was $21.53 \mathrm{mg} \mathrm{g}^{-1}$ clay particles at $160{ }^{\circ} \mathrm{C}$. With a temperature increase to $260^{\circ} \mathrm{C}$, the adsorbed amount of PAAND dropped to $1.75 \mathrm{mg} \mathrm{g}^{-1}$ clay particles. Comparatively, the adsorbed amount of PAAN reduced from $18.06 \mathrm{mg} \mathrm{g}^{-1}$ clay particles to $0.56 \mathrm{mg} \mathrm{g}^{-1}$ clay particles, and the adsorbed amount of PAANS reduced from $20.66 \mathrm{mg} \mathrm{g}^{-1}$ clay particles to $1.50 \mathrm{mg} \mathrm{g}^{-1}$ clay particles when the temperature was increased from $160{ }^{\circ} \mathrm{C}$ to $260{ }^{\circ} \mathrm{C}$, respectively. Obviously, the order of adsorbed amount was PAAND > 


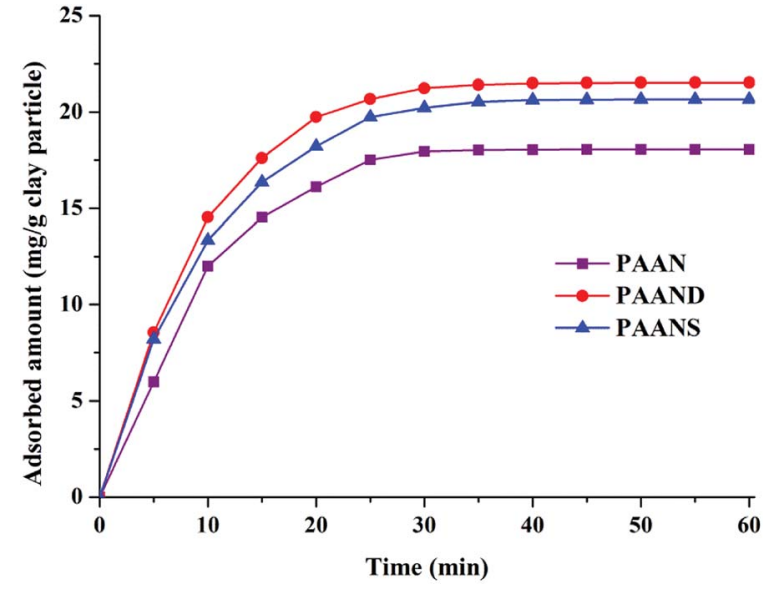

Fig. 12 Dynamic adsorption curves of PAAN, PAAND and PAANS in Na-MMT-based drilling fluid.

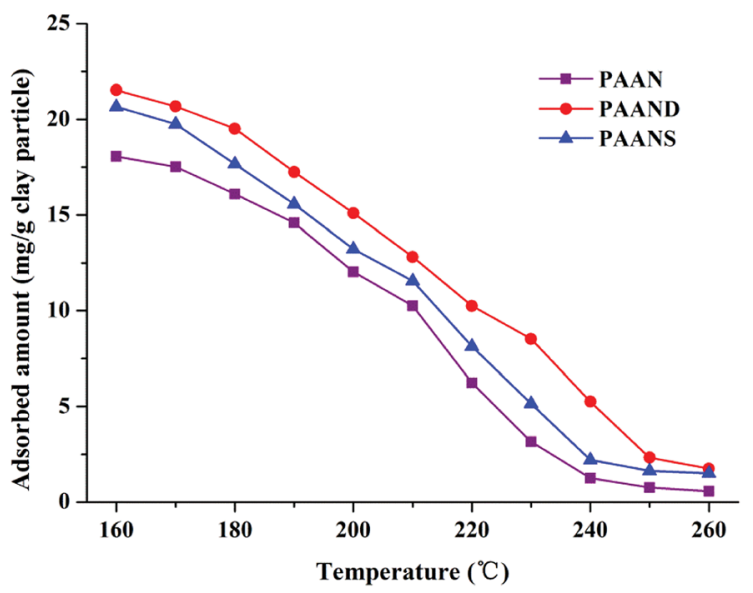

Fig. 13 Effect of temperature on the adsorption capacity of PAAN, PAAND and PAANS.

PAANS > PAAN in the whole temperature range investigated, indicating a stronger interaction between Na-MMT and polymeric fluid loss additives containing rigid monomers. A possible reason for this is that rigid monomers in a polymer molecule can reduce the thermal movement of molecular chains at high temperature, which helps to reduce desorption between the molecular chains and Na-MMT at high temperature.

The particle size distributions of PAAN, PAAND and PAANS in Na-MMT-based drilling fluid are shown in Table 6 and Fig. 14. As indicated in Table 6 and Fig. 14, with increasing temperature, the $D_{10}, D_{50}, D_{90}$ and $D_{\text {av }}$ of PAAN, PAAND and PAANS in Na-MMT-based drilling fluid increased, and the specific surface area (SSA) decreased significantly.

The curve of particle size distribution of PAAN and PAANS changed from having single peak at $160^{\circ} \mathrm{C}$ to having two peaks at $200^{\circ} \mathrm{C}$, which then turned into a single peak again at $240{ }^{\circ} \mathrm{C}$. The curve of the particle size distribution for PAAND changed from having a single peak at $160{ }^{\circ} \mathrm{C}$ to two peaks at $200{ }^{\circ} \mathrm{C}$, and then three peaks $240{ }^{\circ} \mathrm{C}$. The curves indicate a gradual transition towards larger particle sizes, meaning that high temperatures can improve the coalescence of Na-MMT particles. The main reason for this is that high temperature promotes desorption between the polymer and Na-MMT particles, and the Na-MMT particles collide with each other at high temperature and then coalesce. It is also worth noting that polymeric fluid loss additives with rigid monomers, especially in the polymer backbone, are better able to block the transition of Na-MMT particles to large particle sizes in Na-MMT-based drilling fluid. The reason for this phenomenon is that the polymeric fluid loss additive with rigid monomers exhibits strong adsorption on the Na-MMT particle surface and can form a thick hydration film, which effectively restrains the coalescence effect of Na-MMT particles at high temperature.

Filter cakes of PAAN, PAAND and PAANS in Na-MMT-based drilling fluid show various morphologies in Fig. 15. Evident differences in the characteristics of the formed microstructures of the filter cakes can be observed. As indicated in Fig. 15a, c and e, the filter cakes of PAAN, PAAND and PAANS in Na-MMTbased drilling fluid were smooth and uniform on their surfaces after thermal aging at $200{ }^{\circ} \mathrm{C}$. The Na-MMT particles were wrapped by polymer, and the accumulation was relatively dense. There were no significant gullies or pores on the surface of these filter cakes. In contrast, when the thermal aging temperature changed to $240{ }^{\circ} \mathrm{C}$, the surface microstructures of the filter cakes of PAAN, PAAND and PAANS in Na-MMT-based drilling fluid were very different. In comparison to Fig. 15a, Fig. 15b shows that the filter cake surface of PAAN was uneven and friable, with some ravines and pores. Several big Na-MMT

Table 6 Effect of thermal aging temperature on the particle size distribution of PAAN, PAAND and PAANS in Na-MMT-based drilling fluid

\begin{tabular}{|c|c|c|c|c|c|c|}
\hline Na-MMT-based drilling fluid $+2.0 \%$ & 160 & 16.6 & 78.0 & 100.5 & 83.2 & 65355.9 \\
\hline & 240 & 512.8 & 2704.2 & 6333.1 & 2806.0 & 2016.7 \\
\hline \multirow{2}{*}{$\begin{array}{l}\text { Na-MMT-based drilling fluid }+2.0 \% \\
\text { PAAND }\end{array}$} & 160 & 8.7 & 14.8 & 23.4 & 17.3 & 195050.8 \\
\hline & 200 & 12.6 & 22.4 & 86.5 & 23.0 & 126571.3 \\
\hline \multirow{2}{*}{ PAANS } & 200 & 24.1 & 31.7 & 100.0 & 32.0 & 9179.4 \\
\hline & 240 & 91.2 & 365.9 & 1045.3 & 379.6 & 3498.1 \\
\hline
\end{tabular}



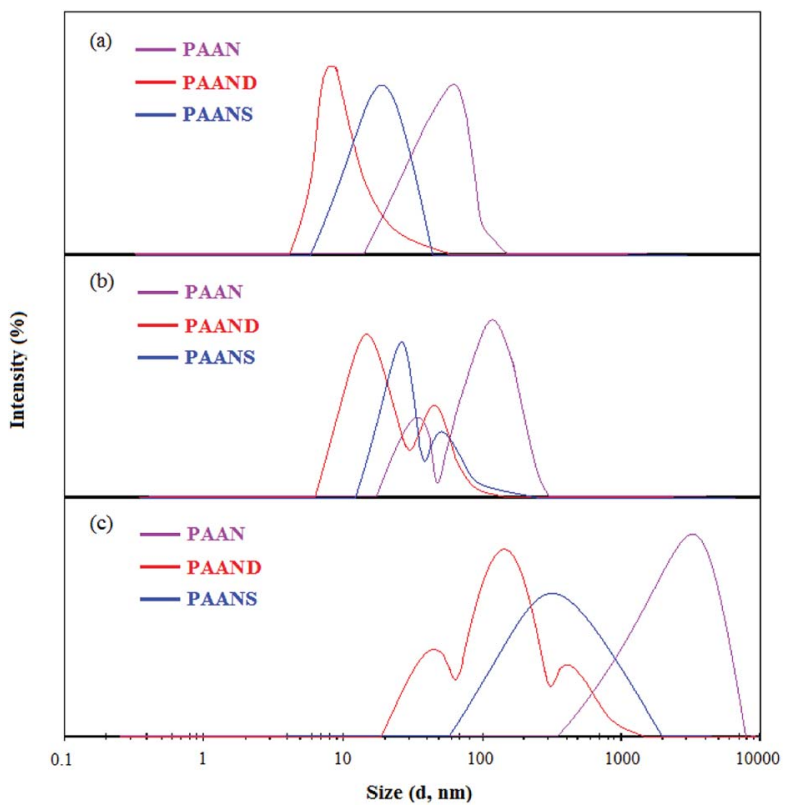

Fig. 14 The curves of particle size distribution of PAAN, PAAND and PAANS in Na-MMT-based drilling fluid after thermal aging tests at (a) $160^{\circ} \mathrm{C}$, (b) $200^{\circ} \mathrm{C}$ and (c) $240{ }^{\circ} \mathrm{C}$.
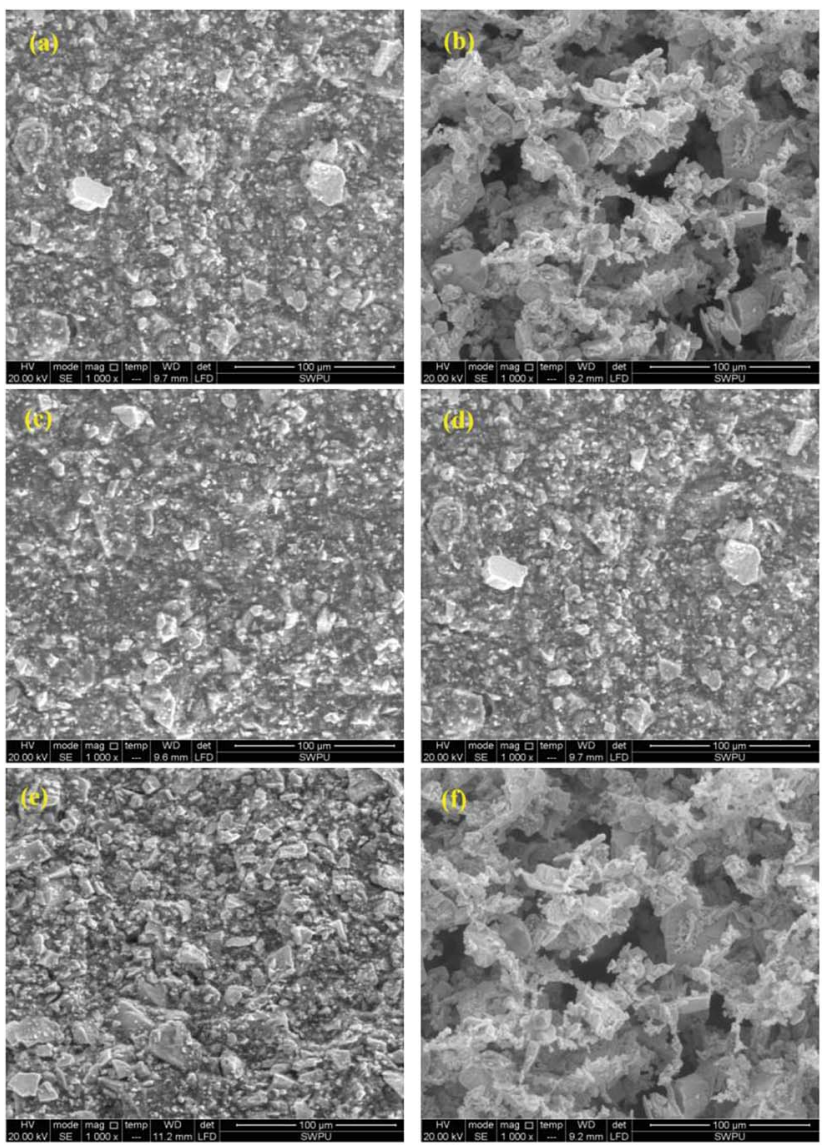

Fig. 15 Filter cake morphologies of PAAN, PAAND and PAANS in $\mathrm{Na}-$ MMT-based drilling fluid after thermal aging tests at different temperatures: (a) PAAN, $200^{\circ} \mathrm{C}$; (b) PAAN, $240^{\circ} \mathrm{C}$; (c) PAAND, $200^{\circ} \mathrm{C}$; (d) PAAND, $240{ }^{\circ} \mathrm{C}$; (e) PAANS, $200^{\circ} \mathrm{C}$; (f) PAANS, $240^{\circ} \mathrm{C}$. particles could be seen, so the Na-MMT-based drilling fluid treated with PAAN exhibited poor dispersion and the filter cake formed was of a poor quality, causing terrible dehydration. In Fig. 15d, although a certain number of large Na-MMT particles appear on the filter cake surface of Na-MMT-based drilling fluid treated with PAAND, small Na-MMT particles are still distributed, and there are no obvious gullies and pores, indicating that the filter cake had a lower permeability and was of better quality after thermal aging at $240{ }^{\circ} \mathrm{C}$. Compared with Fig. 15e, the polymer PAANS on the surface of the filter cake shown in Fig. $15 \mathrm{f}$ is obviously curled, and there are more large Na-MMT particles stacked up. The surface is uneven and friable, and there are larger pores in the surface. These results indicate that the filter cake of the Na-MMT-based drilling fluid treated with PAANS had a high permeability and had lost the ability to control its filtration properties after thermal aging at $240{ }^{\circ} \mathrm{C}$.

An evaluation of the filter cake morphology results shows that the use of polymers with rigid monomers in the backbone as fluid loss additives can effectively keep the fine particle size dispersion in the drilling fluid and improve the filter cake quality. It is of great significance to improve the filtration properties of water-based drilling fluid.

\section{Conclusions}

In this study, the effect of molecular flexibility on the rheological and filtration properties of synthetic polymers as fluid loss additives has been investigated in water-based drilling fluid. Three kinds of polymeric fluid loss additives (PAAN, PAAND and PAANS) were synthesized using HRP as a catalyst under the same conditions. PAAN does not contain any rigid monomers. PAAND is a kind of synthetic polymer with phenyl groups in the backbone, while PAANS is a kind of synthetic polymer with phenyl groups in the side chains. The Na-MMT-based drilling fluids treated with PAAN, PAAND and PAANS presented rheological properties, filtration properties and performance sustainability within the specifications recommended by the American Petroleum Institute. Compared with flexible polymeric fluid loss additives, PAAN, PAAND and PAANS with rigid monomers exhibit better rheological properties, filtration properties and performance sustainability in water-based drilling fluid. In particular, the high temperature resistance of PAAND can reach $240{ }^{\circ} \mathrm{C}$, which indicates that the temperature resistance of a polymeric fluid loss additive can be improved by introducing rigid monomers into the backbone of the polymer molecule to improve its rigidity.

Mechanistic investigations revealed that the improvement is due to the higher adsorption of synthetic polymers containing rigid monomers as fluid loss additives, especially those with rigid monomers introduced into the polymer backbone. This high affinity ensures that polymeric fluid loss additives can strongly encapsulate Na-MMT particles at high temperature, form hydration films on the Na-MMT particle surface and reduce the tendency of Na-MMT particles to collide with each other to form large particles. It can help to maintain a certain number of small Na-MMT particles in the Na-MMT-based drilling fluid, fill the pores in the surfaces of filter cakes and reduce 
the permeability and improve the quality of filter cakes, to control the loss of water from drilling fluid.

\section{Conflicts of interest}

There are no conflicts to declare.

\section{Acknowledgements}

The authors cordially acknowledge the financial support of the National Science and Technology Major Project of China (No. 2016ZX05021-004-002) and the National Natural Science Foundation of China (41702391). Our special thanks go to the State Key Laboratory of Shale Oil and Gas Enrichment Mechanisms Effective Development of China for providing the necessary facilities to carry out this research.

\section{Notes and references}

1 D. V. Peer, F. C. D'Hawse and R. J. Dams, Additive to reduce fluid loss for drilling fluid, US Pat., 2013/8343895 B2, 2013.

2 M. Sadeghalvaad and S. Sabbaghi, Powder Technol., 2015, 272, 113-119.

3 J. K. Fink, Petroleum Engineer's Guide to Oil Field Chemicals and Fluids, Gulf Professional Publishing, Texas, 2012.

4 M. Khodja, J. P. Canselier, F. Bergaya, K. Fourar, N. Cohaut and A. Benmounah, Appl. Clay Sci., 2010, 49, 383-393.

5 Y. M. Wu, B. Q. Zhang, T. Wu and C. G. Zhang, Colloid Polym. Sci., 2001, 279, 836-842.

6 H. P. Quan, H. Li, Z. Y. Huang, T. L. Zhang and S. S. Dai, Int. J. Polym. Sci., 2014, 1-7.

7 O. A. Falose, O. A. Ehinola and P. C. Nebeife, Appl. Clay Sci., 2008, 39, 19-27.

8 V. C. Kelessidis, C. Tsamantaki, A. Michalakis, G. E. Christidid, P. Makri, K. Papanicolaou and A. Foscolos, Fuel, 2007, 86, 1112-1121.

9 M. C. Li, Q. L. Wu, K. L. Song, Y. Qing and Y. Q. Wu, ACS Appl. Mater. Interfaces, 2015, 7, 5006-5016.

10 L. Lin and P. Luo, J. Appl. Polym. Sci., 2015, 132, 4158141591.

11 L. Lin and P. Luo, Appl. Clay Sci., 2018, 163, 10-19.

12 L. M. Zhang, Y. B. Tan and Z. M. Li, Colloid Polym. Sci., 1999, 277, 1001-1004.
13 F. T. G. Dias, R. R. Souza and E. F. Lucas, Fuel, 2015, 140, 711-716.

14 O. T. Salami and J. Plank, J. Appl. Polym. Sci., 2012, 126, 1449-1460.

15 H. M. Ahmad, M. S. Kamal and M. A. AI-Harthi, J. Mol. Liq., 2018, 252, 133-143.

16 X. D. Bai, Y. Yang, D. Y. Xiao, X. L. Pu and X. Wang, J. Appl. Polym. Sci., 2015, 132, 1-9.

17 J. Cao, L. W. Meng, Y. P. Yang, Y. J. Zhu, X. Q. Wang, C. Y. Yao, M. B. Sun and H. Y. Zhong, Energy Fuels, 2017, 31, 11963-11970.

18 K. Plank, A. Brandl and N. R. Lummer, J. Appl. Polym. Sci., 2007, 106, 3889-3894.

19 R. Hill and E. E. Walker, J. Polym. Sci., 1948, 3, 609-630.

20 S. I. Kim, M. Ree, T. J. Shin and J. C. Jung, J. Polym. Sci., Part A: Polym. Chem., 1999, 37, 2909-2921.

21 N. A. Mohamed, Polym. Degrad. Stab., 1994, 44, 33-42.

22 D. J. Liaw, F. C. Chang, M. K. Leung, M. Y. Chou and K. Muellen, Macromolecules, 2005, 38, 4024-4029.

23 T. A. Chen, A. K. Y. Jen and Y. M. Cai, J. Am. Chem. Soc., 1995, 117, 7295-7296.

24 C. D. Varganici, D. Rosu, C. B. Mic, L. Rosu, D. Popovici, C. Hulubei and B. C. Simionescu, J. Anal. Appl. Pyrolysis, 2015, 113, 390-401.

25 Y. Gu, Z. Sun, S. M. Gong, H. Zhang, Q. Gong, L. L. Liu and Y. H. Wang, J. Mater. Sci., 2015, 50, 6552-6558.

26 A. A. Mir, S. Wagner, R. H. Kramer, P. Deglmann and T. Emrick, Polymer, 2016, 84, 59-64.

27 W. Liu, X. Luo, Y. Bao, Y. P. Liu, G. H. Ning, I. Abdelwahab, L. J. Li, C. T. Nai, Z. G. Hu, D. Zhao, B. Liu, S. Y. Quek and K. P. Loh, Nat. Chem., 2017, 9, 563-570.

28 T. Wan, J. Yao, Z. S. Sun, L. Wang and J. Wang, J. Pet. Sci. Eng., 2011, 78, 334-337.

29 X. P. Ma, Z. X. Zhu, W. Shi and Y. Y. Hu, Colloid Polym. Sci., 2016, 295, 53-66.

30 G. V. Chilingarian, E. Alp, R. Caenn, M. A. Salem, S. Uslu, S. Gonzales, R. J. Dorovi, R. M. Mathur and T. F. Yen, Energy Sources, 1986, 8, 233-244.

31 I. S. Dairanieh and S. M. Lahalih, Eur. Polym. J., 1988, 24, 831-835.

32 Q. Chu, P. Y. Luo, Q. F. Zhao, J. X. Feng, X. B. Kuang and D. L. Wang, J. Appl. Polym. Sci., 2013, 128, 28-40. 